\title{
Chemical Indices for Assessing Freshness of Shellfish during Storage
}

\author{
Yoshihiro Yokoyama, ${ }^{* 1}$ Morihiko Sakaguchi, ${ }^{* 2}$ Fumio Kawai,*1 and Masao Kanamori*1 \\ *1 Interdisciplinary Research Institute of Environmental Sciences, Shichihonmatsu, Itsutsuji, Kamigyo, Kyoto 602, Japan \\ ${ }^{* 2}$ Department of Fisheries, Faculty of Agriculture, Kyoto University, Kitashirakawa, Sakyo, Kyoto 606-01, Japan
}

(Received December 9, 1993)

The changes in content of ATP and related compounds were investigated in the muscle of oyster, hard clam, ark-shell, and abalone during storage at $5^{\circ} \mathrm{C}$. We evaluated the efficacy of the $\mathrm{K}, \mathrm{K}^{\prime}$, and A.E.C. values calculated from the content of ATP and related compounds as freshness indices. The degradation patterns of ATP and related compounds were different among the 4 species. ATP decreased rapidly in the oyster and hard clam, but gradually in the ark-shell and abalone. AMP accumulated in all 4 species, while further degradation to IMP and/or HxR occurred markedly in the oyster and arkshell. Although the $\mathrm{K}$ values on the hard clam, ark-shell, and abalone were low at the acceptable stage, the $\mathrm{K}^{\prime}$ value on the hard clam increased slowly but linearly and increased rapidly and linearly for the oyster and ark-shell from the beginning of storage. For the ark-shell and abalone, the A.E.C. value decreased rapidly and linearly during the acceptable stage. The $K^{\prime}$ and A.E.C. values appeared to be useful as freshness indices for shellfishes.

Key words: freshness index, ATP and related compounds, shellfish, storage

The utilization and consumption of marine shellfish are high in Japan, compared with those of other countries. A large amount of shellfish is consumed as fresh material for a variety of dishes, including such popular dishes as sashimi and sushi. Consequently, retention of freshness becomes a matter of serious concern, but the chemical assessment of freshness in postmortem storage for shellfish is less established than that for fishes. Although the $\mathrm{K}$ value ${ }^{1 \prime}$ is a well-known index for measuring the freshness of fish, the value was not considered suitable as a freshness index for shellfishes, such as abalone ${ }^{2)}$ and scallop. ${ }^{3,4)}$ Previously, ${ }^{5)}$ using oyster tissues, we evaluated the efficacy of $\mathrm{K}, \mathrm{K}^{\prime}{ }^{5}$, and adenylate energy charge (A.E.C. ${ }^{6)}$ values as chemical freshness indices during storage. The $\mathrm{K}^{\prime}$ value obtained on the adductor muscle or A.E.C. value done on the mantle, gill, and body trunk was more suitable as a freshness index for oysters. ${ }^{5)}$

In this study, we investigated the postmortem changes in level of ATP and related compounds in the 4 species of marine shellfish, i.e. oysters, hard clams, ark-shells, and abalones, and calculated the 3 indices, $K, K^{\prime}$, and A.E.C. values, in relation to freshness.

\section{Materials and Methods}

\footnotetext{
Materials

Live cultured oysters Crassostrea gigas and hard clams Meretrix lusoria were collected from a culture farm in Matoya bay, Mie Prefecture. Arkshells Anadara broughtonii and abalones Haliotis discus were purchased from a central market in Kyoto. They were artificially purified by placing them in filtered sea water sterilized by ultra-violet rays for $24 \mathrm{~h} .{ }^{7)}$ After shucking and evisceration, each adductor muscle of oyster, or each foot muscle of the ark-shell, hard clam, or abalone was held in a glass vial and stored at $5^{\circ} \mathrm{C}$. At each fixed storage time, 10 specimens were used for the preparation of acid soluble fractions in the same manner as reported previously. ${ }^{5}$
}

Determination of ATP and Related Compounds

ATP and related compounds, ATP, ADP, AMP, IMP, AdR, HxR, and $\mathrm{Hx}$ were determined by HPLC as reported previously. ${ }^{5,8)}$

Calculation of Chemical Indices of Freshness

The $K,{ }^{1)} K^{\prime}{ }^{5)}$ and A.E.C. ${ }^{6)}$ values were calculated from the contents of ATP and related compounds as reported previously. ${ }^{\text {s) }}$

\section{Organoleptic Test}

The sensory ratings of the 4 species were evaluated using the organoleptic test as reported by Matsumoto and Yamanaka. ${ }^{9}$

\section{Results}

\section{Changes in Content of ATP and Related Compounds}

Figure 1 shows the changes in average content of ATP and related compounds in the adductor muscle of the oyster $(n=10)$ stored at $5^{\circ} \mathrm{C}$. During storage, the level of ATP decreased rapidly and reached about $0.1 \mu \mathrm{mol} / \mathrm{g}$ after 1 day of storage. The level of ADP decreased gradually during storage. With the decrease of ATP, a marked accumulation of AMP was found. Then with the decrease of AMP, IMP increased markedly. A small amount of AdR, which is not shown in Fig. 1, was detected on the $1 \mathrm{st}(0.04 \mu \mathrm{mol} / \mathrm{g})$ and 3rd $(0.13 \mu \mathrm{mol} / \mathrm{g})$ day of storage. HxR increased slowly to $1.34 \mu \mathrm{mol} / \mathrm{g}$ until the 10 th day. The Hx level was very low during storage. The total content of ATP and related compounds, about $5 \mu \mathrm{mol} / \mathrm{g}$, was relatively constant during storage.

In the foot muscle of the hard clam, the level of ATP decreased rapidly, reached $0.18 \mu \mathrm{mol} / \mathrm{g}$ after 1 day of storage, and thereafter decreased slowly (Fig. 2). The level of ADP was constant during 1 day of storage, and then decreased gradually. With the rapid decrease of ATP during 1 day of storage, AMP accumulated markedly, remained constant for 5 days, and thereafter decreased. The rate of

The following abbreviations are used: AdR, adenosine; HxR, inosine; Hx, hypoxanthine. 


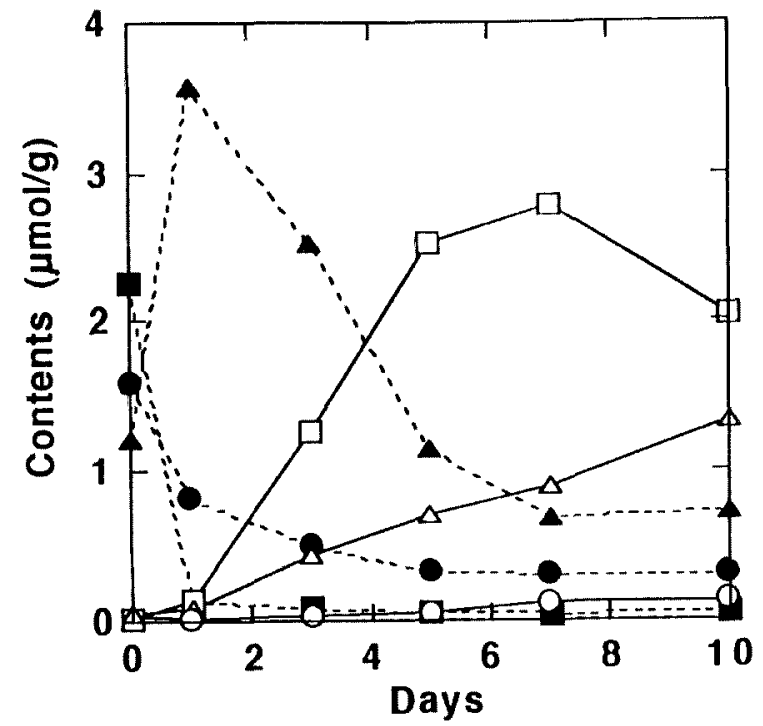

Fig. 1. Changes in average content of ATP and related compounds in the adductor muscle of oyster during storage at $5^{\circ} \mathrm{C}(\mathrm{n}=10)$.

n. ATP;, $\mathrm{ADP} ; \mathbf{A}, \mathrm{AMP} \square, \mathrm{MMP} ; \triangle, \mathrm{HxR} ; \mathrm{O}, \mathrm{Hx}$.

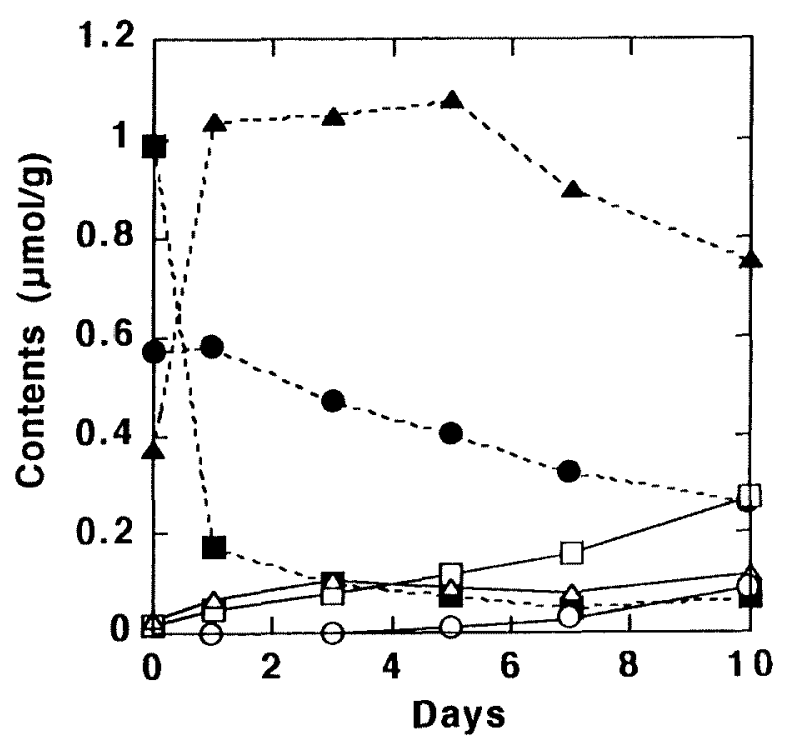

Fig. 2. Changes in average content of ATP and related compounds in the foot muscle of hard clam during storage at $5^{\circ} \mathrm{C}(\mathrm{n}=10)$. Symbols are the same as those in Fig. 1 .

increase in the IMP level in the hard clam muscle was very low compared with that in the oyster muscle. The levels of HxR and $\mathrm{Hx}$ were low; AdR was undetectable. The total content of ATP and related compounds in the hard clam muscle, about $1.9 \mu \mathrm{mol} / \mathrm{g}$, was much lower than that in the oyster muscle.

In the foot muscle of the ark-shell, the level of ATP decreased linearly from 3.12 to $0.10 \mu \mathrm{mol} / \mathrm{g}$ during the 7 days of storage (Fig. 3). The rate of decrease in the ATP level in the ark-shell muscle was very low compared with those in the oyster and hard clam muscle. The level of ADP increased to $1.50 \mu \mathrm{mol} / \mathrm{g}$ on the 1 st day, and then decreased. The level of AMP increased linearly and rapidly until the

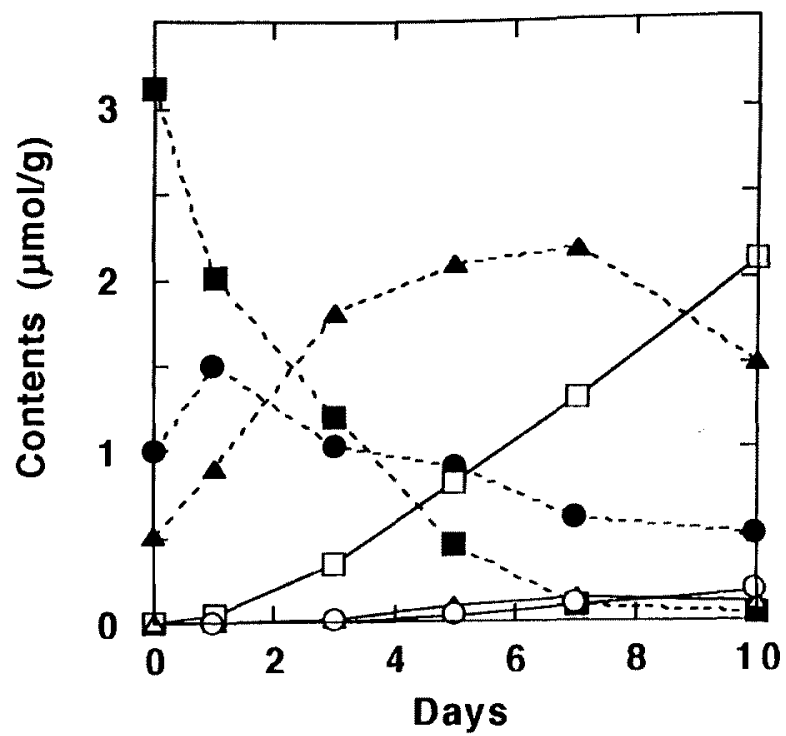

Fig. 3. Changes in average content of ATP and related compounds in the foot muscle of ark-shell during storage at $5^{\circ} \mathrm{C}(\mathrm{n}=10)$. Symbols are the same as those in Fig. 1.

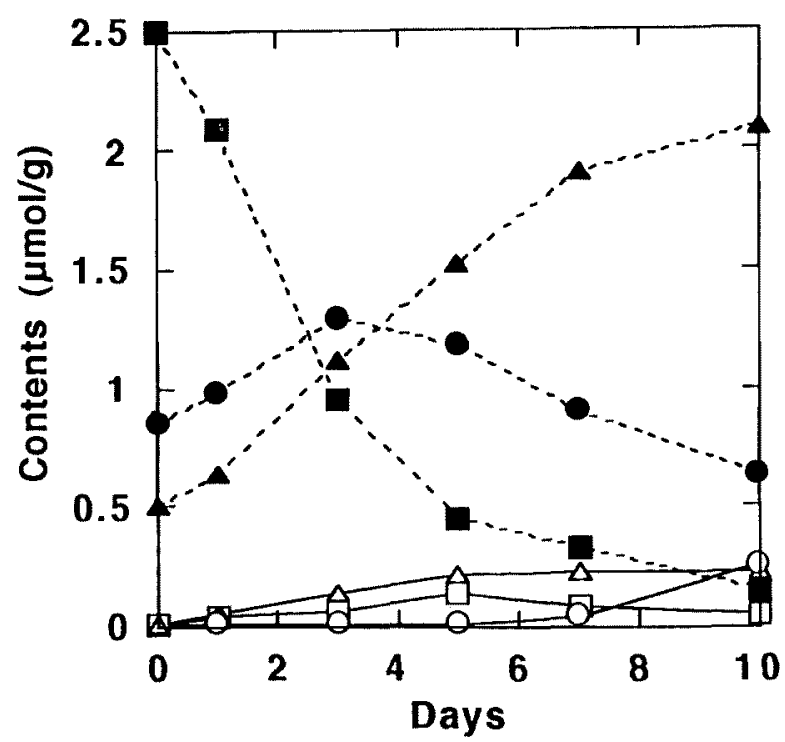

Fig. 4. Changes in average content of ATP and related compounds in the foot muscle of abalone during storage at $5^{\circ} \mathrm{C}(\mathrm{n}=10)$. Symbols are the same as those in Fig. 1.

3rd day, increased slowly until 7 th day, and then decreased. The level of IMP increased linearly from 0.01 to $2.10 \mu \mathrm{mol} / \mathrm{g}$ until the 10th day. A small amount of AdR was also detected (data not shown). The levels of $\mathrm{HxR}$ and $\mathrm{Hx}$ remained low. The total content of ATP and related compounds was about $4.6 \mu \mathrm{mol} / \mathrm{g}$ in the ark-shell muscle.

In the foot muscle of the abalone, the changes in ATP and ADP levels were similar to those in the ark-shell muscle, but the level of AMP increased linearly from 0.50 to 2.10 $\mu \mathrm{mol} / \mathrm{g}$ until the 10 th day (Fig. 4). The level of IMP was low, being about $0.05-0.15 \mu \mathrm{mol} / \mathrm{g}$. A small amount of AdR was also detected as found in the oyster and ark-shell muscle. The level of HxR increased very slowly from 0.01 to 


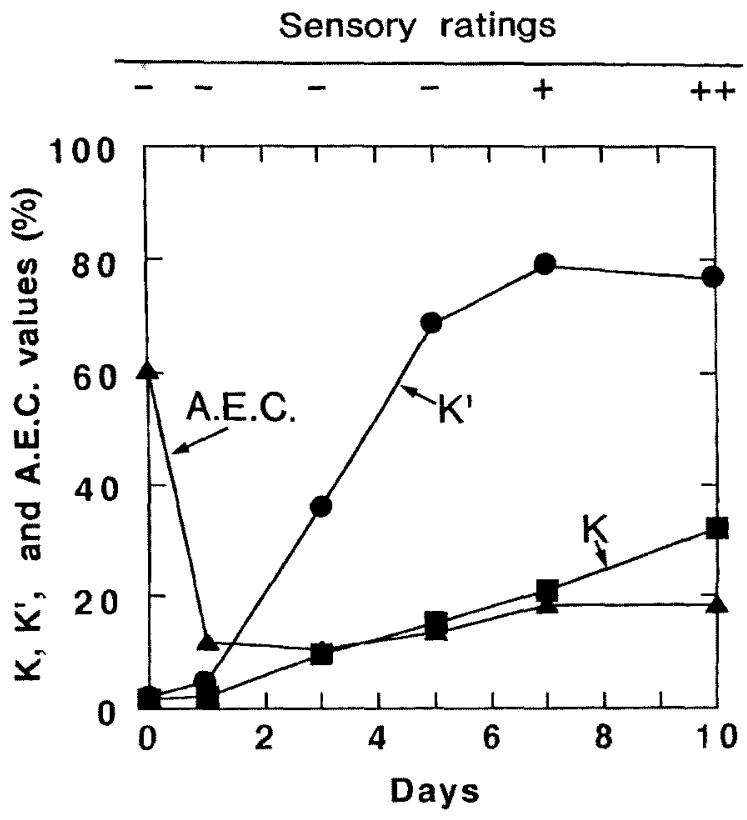

Fig. 5. Changes in average $\mathrm{K}(\mathbf{Q}), \mathrm{K}^{\prime}(\mathbf{O})$, and A.E.C. (A) values in the adductor muscle of oyster during storage at $5^{\circ} \mathrm{C}(\mathrm{n}=10)$ together with sensory ratings.

- , acceptable; + , initial decomposition; ++ , advanced decomposition.

$\frac{\text { Sensory ratings }}{--\infty}-\frac{+}{4}$

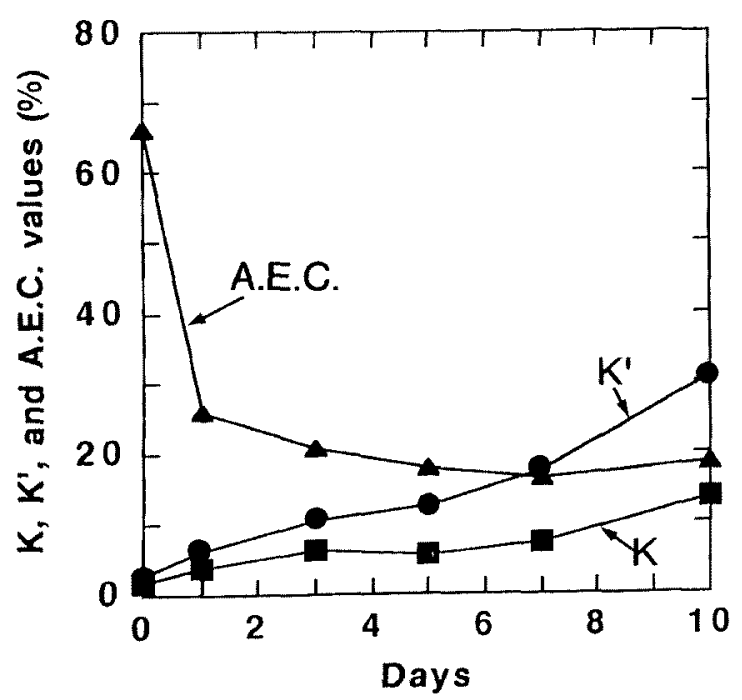

Fig. 6. Changes in average $K, K^{\prime}$, and A.E.C. values in the foot muscle of hard clam during storage at $5^{\circ} \mathrm{C}(\mathrm{n}=10)$ together with sensory ratings.

Symbols are the same as those in Fig. 5.

$0.23 \mu \mathrm{mol} / \mathrm{g}$ during storage. The level of $\mathrm{Hx}$ was constant at a very low level up to the 7 th day, then increased to $0.26 \mu \mathrm{mol} / \mathrm{g}$ on the 10 th day. The total content of ATP and related compounds was about $3.9 \mu \mathrm{mol} / \mathrm{g}$ in the abalone muscle.

\section{Chemical Freshness Indices}

Figures 5-8 show the changes in K, $\mathrm{K}^{\prime}$, and A.E.C. values

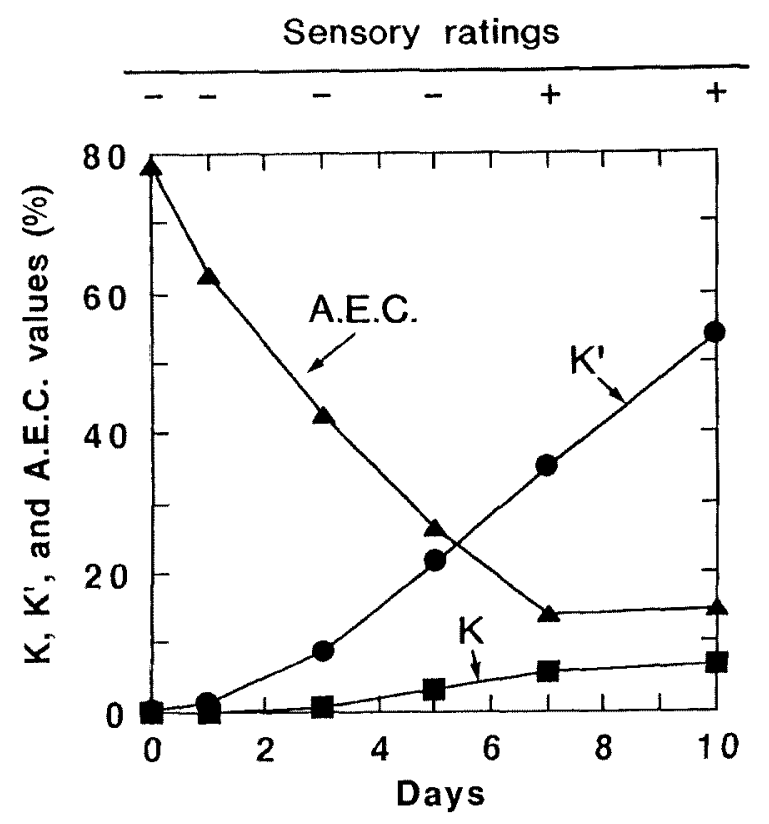

Fig. 7. Changes in average $\mathrm{K}, \mathrm{K}^{\prime}$, and A.E.C. values in the foot muscle of ark-shell during storage at $5^{\circ} \mathrm{C}(\mathrm{n}=10)$ together with sensory ratings.

Symbols are the same as those in Fig. 5.

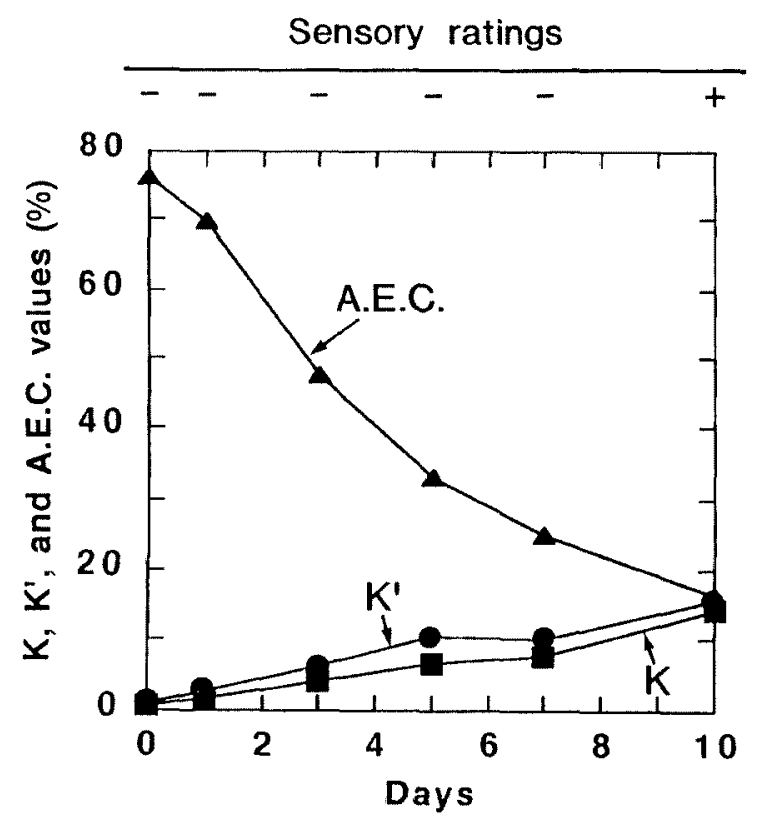

Fig. 8. Changes in average $K, K^{\prime}$, and A.E.C. values in the foot muscle of abalone during storage at $5^{\circ} \mathrm{C}(n=10)$ together with sensory ratings. Symbols are the same as those in Fig. 5.

with sensory ratings obtained on the muscle of oyster, hard clam, ark-shell, and abalone, respectively. On the 7 th day of storage of the oyster, hard clam, and arkshell, or on the 10th day of storage of the abalone, the muscle gave off a faintly putrid smell and this stage was recognized as the stage of initial decomposition. On the oyster muscle, the $\mathrm{K}$ value increased linearly but slowly, and reached the level of $20 \%$ at the initial decomposition stage (Fig. 5). The $\mathrm{K}^{\prime}$ 
value increased linearly and rapidly during an acceptable stage, reached the level of about $80 \%$ at the initial decomposition stage, and thereafter remained constant. The A.E.C. value fell from $60 \%$ to $12 \%$ during 1 day of storage. On the hard clam muscle, the $\mathrm{K}$ value was at low levels during the acceptable stage, and thereafter increased slowly (Fig. 6). The $\mathrm{K}^{\prime}$ value increased slowly but linearly with the changes in $\mathrm{K}$ value obtained on the oyster muscle. The $\mathrm{A}$. E. C. value obtained on the hard clam muscle dropped from $66 \%$ to $26 \%$ during 1 day of storage, thereafter it decreased gradually. On the ark-shell muscle, the $\mathrm{K}$ value increased very slowly and the value was only $6 \%$ at the initial decomposition stage (Fig. 7); the $\mathrm{K}^{\prime}$ value increased rapidly and linearly from the beginning of storage. The A.E.C. value also changed rapidly and linearly from the beginning of storage. In the abalone muscle, the A.E.C. value decreased rapidly and linearly during storage, while the $\mathrm{K}$ and $\mathrm{K}^{\prime}$ value were at low levels during the acceptable stage (Fig. 8).

\section{Discussion}

The average A.E.C. value at time 0 obtained on the muscle of the oyster, hard clam, and ark-shell was 60,66 , and $78 \%$, respectively (Figs. 4-6), and was much higher than that obtained on the muscle of the oyster, hard clam, and ark-shell in the report by Suwetja et al. ${ }^{10)}$ (about 40, 23, and $39 \%$, respectively, which were calculated from the contents of ATP, ADP, and AMP in their report). The energy charge of the adenylate systems has been proposed by Atkinson ${ }^{6)}$ as a fundamental control parameter of metabolism. This concept implies that the conservation of ATP is a major feature of metabolic regulation. The high levels of A.E.C. and ATP in the muscle of the oyster, hard clam, and ark-shell obtained in this investigation indicated that specimens used in this study were in a better condition before the experiment than those in the report by Suwetja et al. ${ }^{10)}$ In fact, in the preliminary experiment, we confirmed that the A.E.C. value at time 0 decreased when the specimens were exposed to air for few days. The A.E.C. value of the muscle of abalone was high, approximately $76 \%$, and was the same level as that reported by Watanabe $e t$ $a .^{2)}$ using the muscle of abalone which was treated within 20 min after collection from the sea.

The degradation patterns of ATP and related compounds differed among the 4 species. ATP decreased rapidly in the muscle of oyster (Fig. 1) and hard clam (Fig. 2), but gradually in the muscle of ark-shell (Fig. 3) and abalone (Fig. 4) as did those in the mantle, gill, and body trunk of oyster. ${ }^{5)}$ AMP accumulated in the muscle of all 4 species, while further degradation to IMP and/or HxR occurred markedly in the muscle of the oyster and ark-shell. These findings suggested that the activities of the enzyme systems responsible for the degradation of ATP, ADP, AMP, and IMP, that is ATPase, myokinase, AMP deaminase, and 5 -nucleotidase, respectively, differed among the 4 species. Both IMP and AdR were detected in the muscle of the oyster, ark-shell, and abalone. We previously reported the two pathways of AMP degradation in the oyster muscle. ${ }^{5}$ Watanabe et al. $^{2)}$ also reported the two pathways in the abalone muscle. In this study, we also found two pathways of AMP degradation, an IMP pathway and an AdR pathway, in the foot muscle of the ark-shell during storage. In the foot muscle of the hard clam, a small amount of IMP was detected, but AdR was undetectable, suggesting the IMP pathway functions predominantly during storage.

As the chemical freshness indices for oyster, hard clam, ark-shell, and abalone, K, K', and A.E.C. values were calculated from the levels of ATP and related compounds (Figs. 5-8). We previously reported that the $\mathrm{K}^{\prime}$ value in the adductor muscle or the A.E.C. value in the mantle, gill, and body trunk that showed a rapid and linear change from the beginning of storage might be useful as a freshness indicator for the oyster. ${ }^{5)}$ In this study, we confirmed the findings that the $\mathrm{K}^{\prime}$ value in the oyster muscle was useful as a freshness indicator because of its linear and rapid increase during the acceptable stage (Fig. 5). In the foot muscle of the hard clam, the $\mathrm{K}$ value showed little increase during the acceptable stage and the A.E.C. value did not change linearly (Fig. 6). The $\mathbf{K}^{\prime}$ value increased slowly from the beginning of storage to about $20 \%$ by the initial decomposition stage. However, the $\mathrm{K}^{\prime}$ value in the muscle of hard clam was useful as a freshness indicator because of its linear increase during the acceptable stage, as suggested by Sakaguchi et al. ${ }^{11)}$ on the $\mathrm{K}$ value on the muscle of oyster C. gigas, and by Matsumoto and Yamanaka") on the $\mathrm{K}$ value on the muscle of prawn Penaleus japonicus. Watanabe et al. $^{2)}$ reported that the $\mathrm{K}$ value on the muscle of abalone was not suitable as a freshness index, since the value did not change from the beginning of storage and the rate of increase was slow. In this study, the $K$ value on the abalone muscle also increased very slowly (Fig. 7) and was not considered to be suitable as a freshness index. Although the $K^{\prime}$ value also increased very slowly, the A.E.C. value changed rapidly and linearly from the beginning of storage and seemed to be very useful as a freshness index. In the ark-shell, the A.E.C. and K' values seemed to be very useful as freshness indices because of their linear and rapid changes from the beginning of storage (Fig. 8). In conclusion, the $\mathrm{K}$ value could not be used as a freshness index for the hard clam, ark-shell, or abalone. The $\mathrm{K}^{\prime}$ value and A.E.C. value were potential indices for the freshness of shellfishes such as oyster, hard clam, ark-shell, and abalone, and thus an adequate index for respective species of shellfish could be used. However, these results on the freshness indices calculated from the contents of ATP and related compounds were obtained from investigations using muscles stored at $5^{\circ} \mathrm{C}$. An interesting effect of storage temperature on ATP degradation, a faster ATP degradation at a lower storage temperature, has been observed in the muscle of shellfishes. ${ }^{2-4)}$ In order to determine whether or not the $K^{\prime}$ and A.E.C. values can be applied to shellfishes as freshness indices at various temperature, further study is needed.

Acknowledgments We thank Misses N. Terada and M. Tanioka for skilled technical assistance. The oysters and clams were obtained through the excellent cooperation of Mr. H. Tahara, Matoya Bay Oyster Research Laboratory.

\section{References}

1) T. Saito, K. Arai, and M. Matsuyoshi: A new method for estimating the freshness of fish. Nippon Suisan Gakkaishi, 24, 749-750 (1959).

2) H. Watanabe, H. Yamanaka, and H. Yamakawa: Post-mortem 
biochemical changes in the muscle of disk abalone during storage. Nippon Suisan Gakkaishi, 58, 2081-2088 (1992).

3) M. Iwamoto, H. Yamakawa, S. Watabe, and K. Hashimoto: Changes in ATP and related breakdown compounds in the adductor muscle of "itayagai" scallop Pecten albicans during storage at various temperatures. Nippon Suisan Gakkaishi, 57, 153-156 (1991).

4) K. Kawashima and H. Yamanaka: Effects of storage temperatures on the postmortem biochemical changes in scallop adductor muscle. Nippon Suisan Gakkaishi, 58, 2175-2180 (1992).

5) Y. Yokoyama, M. Sakaguchi, F. Kawai, and M. Kanamori: Changes in concentration of ATP-related compounds in various tissues of oyster during ice storage. Nippon Suisan Gakkaishi, 58, 2125-2136 (1992).

6) D. E. Atkinson: The energy charge of the adenylate pool as a regulatory parameter. Interaction with feedback modifiers. Biochemistry, 7, 4030-4034 (1968).

7) T. Satoh: Purification of edible oyster. Rep. Fac. Fish. Mie Pref.
Univ., 3, 627-632 (1960).

8) Y. Yokoyama, M. Sakaguchi, F. Kawai, and M. Kanamori: A method for the determination of ATP and its related compounds in oyster by HPLC. Ann. Rep. Interdiscipl. Res. Inst. Environ. Sci., 12, $1-6(1992)$.

9) M. Matsumoto and H. Yamanaka: Post-mortem biochemical changes in the muscle of kuruma prawn during storage and evaluation of the freshness. Nippon Suisan Gakkaishi, 56, 1145-1149 (1990)

10) I. K. Suwetja, K. Miyazawa, and K. Ito: Changes in content of ATP-related compounds, homarine, and trigonelline in marine invertebrates during ice storage. Nippon Suisan Gakkaishi, 55 , 559-566 (1989).

11) M. Sakaguchi, K. Yamashita, and M. Murata: The accumulation of AMP and IMP in the adductor muscle of oyster during storage. Proceedings of International Meeting on "Chilling and Freezing of New Fish Products", Aberdeen, Scotland, 1990, pp. 140-146. 